\title{
Evaluation of the Ability of CRRT to Remove Amino Acids According to Differences in the Hemofilter and Filtration Volume
}

\author{
Hiroomi Tatsumi ${ }^{1 *}$, Shinya Chihara ${ }^{2}$, Satoshi Kazuma ${ }^{1}$, Masayuki Akatsuka ${ }^{1}$ and Yoshiki \\ Masuda $^{1}$ \\ ${ }^{1}$ Department of Intensive Care Medicine, Sapporo Medical University School of Medicine, Japan \\ ${ }^{2}$ Division of Clinical Engineering, Sapporo Medical University Hospital, Japan
}

*Corresponding author: Hiroomi Tatsumi, Department of Intensive Care Medicine, Sapporo Medical University School of Medicine, South 1 West 16, Chuo-ku, Sapporo, Hokkaido, 060-8543, Japan

\section{ARTICLE INFO}

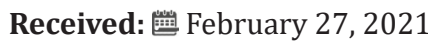

Published: 蔧 March 04, 2021

Citation: Hiroomi T, Shinya C, Satoshi K, Masayuki A, Yoshiki M. Evaluation of the Ability of CRRT to Remove Amino Acids According to Differences in the Hemofilter and Filtration Volume. Biomed J Sci \& Tech Res 34(3)-2021. BJSTR. MS.ID.005541.

Keywords: Continuous Hemofiltration; Hemofilter; Filtration Volume; Amino Acid Removal

Abbreviations: CRRT: Continuous Renal Replacement Therapy; AN69ST: Acrylonitrile-Co-Methallyl Sulfonate Surface-Treated; TPN: Total Parenteral Nutrition; CHF: Continuous Hemofiltration; PS: Polysulfone; PMMA: Polymethyl Methacrylate; QF: Flow Rate of Replacement Fluid

\section{ABSTRACT}

Background: The ability of continuous renal replacement therapy (CRRT) to remove amino acids with different hemofilters and filtration volumes was investigated by using an experimental model of closed circulation.

Materials and Methods: CRRT was performed for 4 hours with recirculation in the total parenteral nutrition solution bag, and concentrations of amino acids in the bag were determined. Polysulfone (PS), polymethyl methacrylate (PMMA) and acrylonitrileco-methallyl sulfonate surface-treated (AN69ST) membranes were used as hemofilters. The modality of CRRT was continuous hemofiltration (CHF), and the flow rate of the test solution and flow rate of the replacement fluid (QF) were set to $100 \mathrm{ml} / \mathrm{min}$ and $600 \mathrm{~mL} /$ $\mathrm{hr}$, respectively. When using the PS membrane, QF was set to $2000 \mathrm{~mL} / \mathrm{min}$.

Results: The concentrations of amino acids at QF of $600 \mathrm{~mL} / \mathrm{hr}$ decreased with time, but there was no remarkable difference depending on the hemofilter material or the electric charge states of amino acids. The concentrations of amino acids at QF of 2000 $\mathrm{mL} / \mathrm{hr}$ markedly decreased earlier than those at $600 \mathrm{~mL} / \mathrm{hr}$ and became under the lower detection limit after 120 minutes.

Conclusions: The number of amino acids removed as small molecules may not be different regardless of the type of hemofilter. Caution should be taken when using highvolume CHF because the concentrations of amino acids clearly decreased with increase in the filtration volume.

\section{Background}

Appropriate nutritional therapy is closely associated with the complication rate and clinical course in critically ill patients $[1,2]$. Sufficient amounts of proteins and amino acids are crucial for critically ill patients. On the other hand, continuous renal replacement therapy (CRRT) is used to support impaired renal function and to regulate mediators in critically ill patients [35]. During CRRT, small molecular weight substances including electrolytes, administered drugs and nutrients may be removed by mechanisms such as filtration and diffusion. Increased removal of essential substances by high-volume CRRT has been suggested to induce reduction of the drug treatment effect and deterioration of nutrition status [6-8]. In recent years, attention has been given to an acrylonitrile-co-methallyl sulfonate surface-treated (AN69ST) membrane as a membrane that efficiently adsorbs cytokines [9]. In addition, albumin may not be adsorbed easily since the membrane is negatively charged [10]. However, it has not been determined whether the AN69ST membrane adsorbs amino acids and whether its adsorption ability changes according to difference in the charge 
state of amino acids. In this study, we evaluated the ability of CRRT to remove amino acids depending on differences in the hemofilter and filtration volume by using an experimental model of a closed circuit.

\section{Materials and Methods}

A closed circulation system of CRRT was constructed by using a high-calorie total parenteral nutrition (TPN) solution formulated with amino acids (ELNEOPA-NF No. 2 Injection, Otsuka Pharmaceutical Factory, Inc., Naruto, Japan) as a test solution. The composition and concentrations of amino acids in ELNEOPANF No. 2 Injection are shown in Table 1. The modality of CRRT was continuous hemofiltration (CHF) using SUBPACK-Bi (Nipro Tokyo, Japan) as a replacement fluid, and the flow rate of the test solution was set to $100 \mathrm{~mL} / \mathrm{min}$. CRRT was performed for 4 hours with recirculation in the test solution bag, and concentrations of various amino acids were determined by liquid chromatography/ mass spectrometry. The sampling point of the test solution was just before the hemofilter, and samples were collected at $0,15,30,60$, 120,180 and 240 minutes after starting recirculation. Three types of membranes including polysulfone (PS), polymethyl methacrylate (PMMA) and AN69ST membranes were used as hemofilters for the experimental CRRT. The flow rate of the replacement fluid (QF) was set to $600 \mathrm{~mL} / \mathrm{hr}$ (which is the amount for insurance adaptation in Japan). In addition, when using the PS membrane, changes in concentrations of amino acids were determined at a QF of $2000 \mathrm{~mL} /$ $\min$.

Table 1.

\begin{tabular}{|c|c|c|c|}
\hline \multirow{2}{*}{ Amino acids } & MW & \multicolumn{2}{|c|}{ Concentration } \\
\cline { 2 - 4 } & $\mathbf{( k D a )}$ & $\mathbf{( m g / m L )}$ & 32020 \\
\hline L-Leucine & 131.17 & 4.20 & 18297 \\
\hline L-Isoleucine & 131.17 & 2.40 & 20487 \\
\hline L-Valine & 117.15 & 2.40 & 21547 \\
\hline L-Lysine & 146.19 & 3.15 & 14355 \\
\hline L-Threonine & 119.12 & 1.71 & 2938 \\
\hline L-Tryptophan & 204.23 & 0.60 & 7841 \\
\hline L-Methionine & 149.21 & 1.17 & 2476 \\
\hline L-Cysteine & 121.16 & 0.30 & 12713 \\
\hline L-Phenylalanine & 165.19 & 2.10 & 828 \\
\hline L-Tyrosine & 181.19 & 0.15 & 18083 \\
\hline L-Arginine & 174.2 & 3.15 & 9668 \\
\hline L-Histidine & 155.15 & 1.50 & 26939 \\
\hline L-Alanine & 89.09 & 2.40 & 13029 \\
\hline L-Proline & 115.13 & 1.50 & 8564 \\
\hline L-Serine & 105.09 & 0.90 & 23578 \\
\hline Glycine & 75.07 & 1.77 & 2254 \\
\hline L-Aspartic Acid & 133.1 & 0.30 & 2039 \\
\hline L-Glutamic Acid & 147.13 & 0.30 & \\
\hline
\end{tabular}

\section{Results}

Concentrations of 18 amino acids in thehigh-calorie TPN solution were measured. Since changes in the concentrations of amino acids showed almost the same trends, the changes in concentrations of alanine (neutral electric charge), glutamic acid (negative electric charge) and arginine (positive electric charge), which were selected from differences in the charge state of amino acids, are presented. The concentration of alanine decreased with time, but there was no remarkable difference in alanine concentrations among the three hemofilters (Figure 1). Alanine concentration at QF of 2000mL/ $\mathrm{hr}$ (high volume) markedly decreased earlier than that at $600 \mathrm{~mL} /$ $\mathrm{hr}$ and became under the lower detection limit after 120 minutes. The concentrations of glutamic acid and arginine decreased with the same tendency regardless of the electric charge state, and there was no difference in the amino acid concentrations with the different hemofilter materials. 


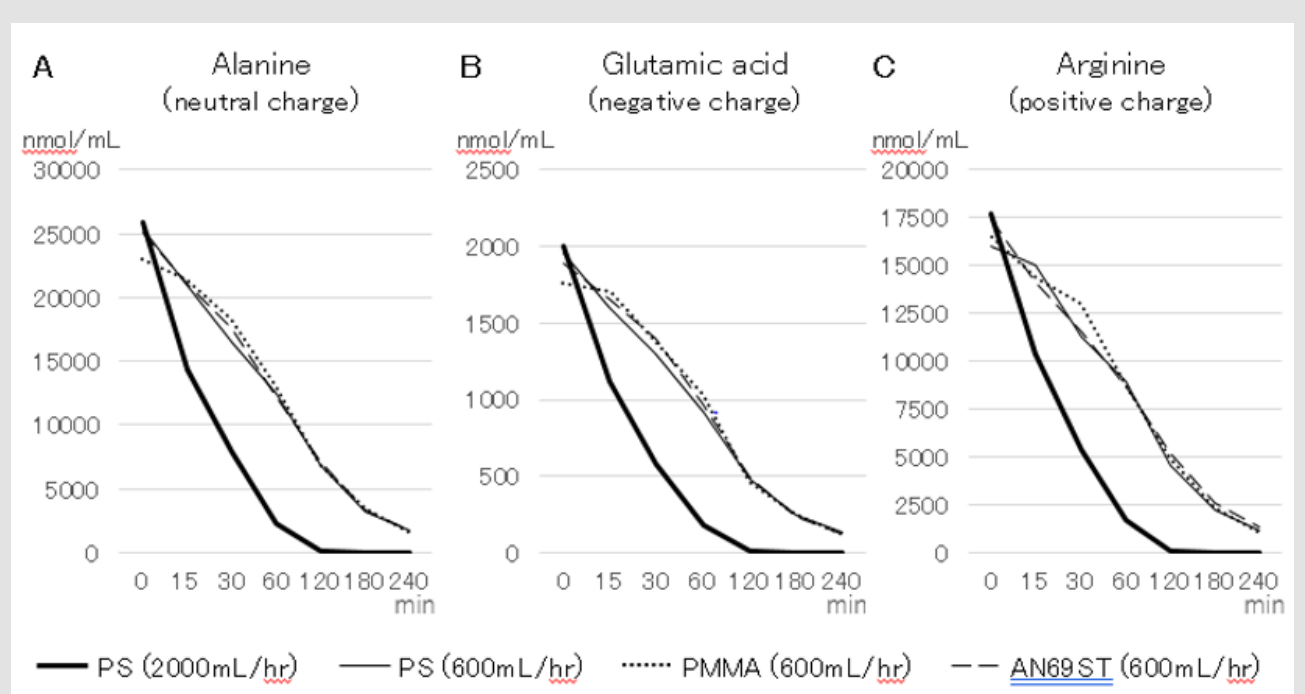

Figure 1.

\section{Discussion}

We evaluated the ability of CRRT to remove amino acids using a closed circuit and a high-calorie TPN solution as the test solution. After starting CRRT, concentrations of amino acids gradually decreased, but there was no difference depending on the type of hemofilter or electric charge state of amino acids. However, decreased concentrations of amino acids at an increased filtration volume indicated that high-volume CRRT may increase the amount of amino acids removed. In this study, the ability of CRRT to remove amino acids was investigated by using three types of hemofilters: a PS membrane as a filtration membrane and PMMA and AN69ST membranes as adsorption membranes. For large molecular weight substances such as cytokines, the mechanism of removal seems to be mainly filtration in the PS membrane and adsorption in the PMMA and AN69ST membranes. The AN69ST membrane, which has been developed as a cytokine adsorption membrane, is designed to have a negatively electric charged surface itself and to have reduced ability for removal of albumin, which is negatively charged.

Since the amino acids evaluated in this study were small molecular weight substances, it was considered that the membrane material of the hemofilter and the electric charged state had no influence on the ability of CRRT to remove amino acids. On the other hand, the results suggested that the amount of amino acids removed increases with an increase in filtration volume. It has been reported that increased filtration volume up to $25 \mathrm{~mL} / \mathrm{kg} / \mathrm{hr}$ may increase the therapeutic effect compared with $\mathrm{QF}$ of $600 \mathrm{~mL} / \mathrm{hr}$ (equivalent to $12 \mathrm{~mL} / \mathrm{kg} / \mathrm{hr}$ for body weight of $50 \mathrm{~kg}$ ), which is the amount for insurance adaptation in Japan [11]. However, it is considered that removal of small essential substances such as amino acids cannot be overlooked if the volume of filtration is increased up to $2000 \mathrm{~mL} / \mathrm{hr}$ (equivalent to $40 \mathrm{~mL} / \mathrm{kg} / \mathrm{hr}$ for body weight of $50 \mathrm{~kg}$ ).
We perform tapering-CHF that increases the filtration volume in the early stage of sepsis and then gradually decrease its filtration volume according to the hemodynamic state or changes in lactate concentration [12].

The results of this study indicate that it is important to gradually decrease the increased filtration volume as soon as possible after reaching a stabilized state of disease by taperingCHF. Furthermore, it is necessary to increase the number of amino acids and proteins from parenteral and enteral nutrition to avoid loss of amino acids when performing tapering CHF. This study has several limitations. First, there was no influence of clogging of the hemofilter due to plasma protein and blood cells since a clinically available high-calorie TPN solution was used as the test solution in this study. Second, the results of this study cannot be directly applied to changes of amino acid concentration in clinical patients undergoing CRRT. Since amino acids are supplied by generation in the liver and administration from parenteral and enteral feeding, the concentrations of amino acids do not rapidly decrease and may be clinically different. Finally, in clinical settings, it is necessary to consider leakage of amino acids from circulating blood because of hypervascular permeability in critically ill patients. Such mechanisms were not included in our experimental model.

\section{Conclusions}

The ability of CRRT to remove amino acids depending on the type of hemofilter and the volume of filtration was evaluated by using closed circuit models. The amount of amino acids removed as small molecules may not be different regardless of the type of hemofilter. However, caution should be taken when using highvolume CHF because the concentrations of amino acids clearly decreased with increase in the filtration volume. 


\section{References}

1. McClave SA, Taylor BE, Martindale RG, Gordon S Sacks, Pamela R Roberts, et al. (2016) Guidelines for the Provision and Assessment of Nutrition Support Therapy in the Adult Critically Ill Patient: Society of Critical Care Medicine (SCCM) and American Society for Parenteral and Enteral Nutrition (A.S.P.E.N.). JPEN J Parenter Enteral Nutr 40(2): 159-211.

2. Singer P, Blaser AR, Berger MM, Wojciech Szczeklik, Stephan C Bischoff, et al. (2019) ESPEN guideline on clinical nutrition in the intensive care unit. Clin Nutr 38(1): 48-79.

3. Ronco C, Tetta C, Mariano F, Vince d'Intini, Rinaldo Bellomo, et al. (2003) Interpreting the mechanisms of continuous renal replacement therapy in sepsis: the peak concentration hypothesis. Artif Organs 27(9): 792801.

4. Nakada TA, Oda S, Matsuda K (2008) Continuous hemodiafiltration with PMMA Hemofilter in the treatment of patients with septic shock. Mol Med 14(5): 257-263.

5. Chihara S, Masuda Y, Tatsumi H (2019) Evaluation of pre- and postdilution continuous veno-venous hemofiltration on leukocyte and platelet function in patients with sepsis. Int J Artif Organs 42(1): 9-16.

6. Scheinkestel CD, Adams F, Mahony L, I Nyulasi, DV Tuxen, et al. (2003) Impact of increasing parenteral protein loads on amino acid levels and balance in critically ill anuric patients on continuous renal replacement therapy. Nutrition 19: 733-740.

\section{ISSN: 2574-1241}

DOI: 10.26717/BJSTR.2021.34.005541

Hiroomi Tatsumi. Biomed J Sci \& Tech Res

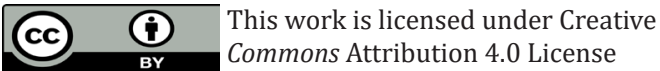

Submission Link: https://biomedres.us/submit-manuscript.php
7. Druml W (1999) Metabolic aspects of continuous renal replacement therapies. Kidney Int Suppl 72: 56-61.

8. Wooley JA, Btaiche IF, Good KL (2005) Metabolic and nutritional aspects of acute renal failure in critically ill patients requiring continuous renal replacement therapy. Nutr Clin Pract 20(2): 176-191.

9. Shiga H, Hirasawa H, Nishida O, Yoshihiko Kikuchi, Nobuo Fuke, et al. (2014) Continuous hemodiafiltration with a cytokine-adsorbing hemofilter in patients with septic shock: a preliminary report. Blood Purif 38(3): 211-218.

10. Furuta M, Kuragano T, Kida A, Akihide Matsumoto, Takeshi Nakanishi, et al. (2011) A crossover study of the acrylonitrile-co-methallyl sulfonate and polysulfone membranes for elderly hemodialysis patients: the effect on hemodynamic, nutritional, and inflammatory conditions. ASAIO J 57(4): 293-299.

11. Uchino S, Bellomo R, Morimatsu H, Claudio Ronco, John A Kellum, et al. (2007) Continuous renal replacement therapy: a worldwide practice survey. The beginning and ending supportive therapy for the kidney (B.E.S.T. kidney) investigators. Intensive Care Med 33(9): 1563-1570.

12. Chihara S, Shimada T, Tatsumi H (2017) Evaluation of characteristics in continuous hemofiltration using three different material of hemofilter and filtration flow rate. J Jpn Soc Blood Purif Crit Care 8: 127-131.

$\begin{array}{ll}\text { BIOMEDICAL } & \text { Assets of Publishing with us } \\ \text { RESEARCHES } & \text { - Global archiving of articles } \\ \text { - Immediate, unrestricted online access }\end{array}$

